\title{
Clinical and demographic differences between patients with manic, depressive, and schizophrenia- spectrum psychoses presenting to Early Intervention Services in London
}

Adisha Kapila1, Helen L. Fisher ${ }^{2}$, Sonia Johnson ${ }^{3,4}$, Barnaby Major ${ }^{5,6}$, Nikola Rahaman ${ }^{7}$, John Joyce ${ }^{8}$, Nick Chamberlain-Kent ${ }^{9}$, Jo Lawrence ${ }^{10}$, Allan H Young ${ }^{2}$, James M Stone ${ }^{\star 2}$

${ }^{1}$ Faculty of Life Sciences \& Medicine, King's College London, London, UK.

${ }^{2}$ Institute of Psychiatry, Psychology \& Neuroscience, King's College London, London, UK.

${ }^{3}$ Division of Psychiatry, University College London, London, UK.

${ }^{4}$ Camden and Islington NHS Foundation Trust, London, UK.

${ }^{5}$ EQUIP, Hackney, East London NHS Foundation Trust, London, UK.

${ }^{6}$ Herefordshire Early Intervention Service, ${ }^{2}$ gether NHS Foundation Trust, Herefordshire, UK.

${ }^{7}$ Kensington, Chelsea, Westminster and Brent Early Intervention Service, Central \& North West London NHS Foundation Trust, London, UK.

${ }^{8}$ Lewisham Early Intervention Service, South London and Maudsley NHS Foundation Trust, London, UK.

${ }^{9}$ Wandsworth Early Intervention Service, South West London \& St Georges' Mental Health NHS Trust, London, UK.

${ }^{10}$ STEP, Southwark, South London and Maudsley NHS Foundation Trust, London, UK.

* Address correspondence to: Dr James Stone, Centre for Neuroimaging Sciences, Institute of Psychiatry Psychology \& Neuroscience, 16 De Crespigny Park, London SE5 8AF, UK.

Tel: +44 2032283053. Email: james.m.stone@kcl.ac.uk.

Abstract word count: 221 words

Main text word count: 2518 words 


\section{Acknowledgements}

This work was supported by the NIHR Biomedical Research Centre for Mental Health at the South London and Maudsley NHS Foundation Trust and Institute of Psychiatry, King's College London. The research received no specific grant from any funding agency, commercial or not for profit sectors. Initial pilot work on the MiData package within Camden \& Islington Early Intervention Services was supported by Islington Primary Care Trust. We are extremely grateful to clinicians and patients from the participating teams for their time and enthusiasm. We would particularly like to acknowledge the contributions of Kate Theodore, Tom Grange, Katharine McLoughlin, Lorna Hobbs, Peggy Papada, Sally Bloy, Kelso Cratsley, Laurence Church, Rhianne Doherty, Sharif Ghali, Sasha Gold, Farhana Mann, Andrew Tapfumaneyi, Denise Bevan, Lisa Gaiotto, Peter Bailey, Jana Advani, Teuta Rexhepi, Charlie Heriot-Maitland, Mima Simic and Sujata Soni to collection of data in the individual sites. Thanks also to members of LEIRN, especially Paddy Power, Swaran Singh, Aurelie Freeman, Maxine Sacks, Gillian Paul, Brock Chisholm, Emma Stinton and Jim O'Donnell for their contributions to the development and implementation of the package. 


\section{Abstract}

Aim: To investigate the relationship between the presenting clinical and demographic characteristics in first episode psychosis patients with their clinical diagnostic grouping 1 year later.

Methods: Data from 1014 patients from seven London-based Early Intervention Services were extracted from the MiData audit database. Associations between clinical and demographic measures at presentation and clinical diagnosis made at 1 year were assessed with ANOVA and Chi-square tests.

Results: The sample comprised $76 \%$ of patients with schizophrenia-spectrum diagnoses, $9 \%$ with manic psychoses, and 6\% with depressive psychoses. Compared to the other two groups, patients who were diagnosed as having manic psychosis were younger, with higher education and shorter duration of untreated psychosis, and had higher Young Mania Rating Scale scores at presentation and lower PANSS-N scores. Patients diagnosed at 1 year as having depressive psychosis were older and more likely to be white, with the lowest PANSS-positive scores at baseline. Patients diagnosed at 1 year as having schizophrenia spectrum diagnoses were more likely to be black males. Patients in the 3 diagnostic subgroups of psychosis differed on both clinical and demographic characteristics at presentation.

Conclusions: There were significant clinical and demographic differences at presentation between first episode psychosis patients who received different clinical diagnoses at 1 year. Future work will determine the extent to which these differences can be used to guide clinical care.

Key words: Schizophrenia, Manic Psychosis, Bipolar Affective Disorder, Depressive Psychosis, Major Depressive Disorder, First Episode Psychosis, Diagnosis 


\section{Introduction}

Clinical diagnosis is integral to optimal patient care,${ }^{1}$ but in psychiatry the establishment of a clear diagnosis may be difficult. ${ }^{2}$ One reason for this is the fact that many conditions can present with similar and overlapping symptoms. ${ }^{3}$ Psychotic symptoms, notably hallucinations and delusions, are experienced in both affective and non-affective conditions, but differentiating between these subtypes in first-episode psychosis (FEP) patients is often problematic at presentation. ${ }^{4}$ Although schizophrenia spectrum (SZ) and affective psychoses have different genetic risk factors, as well as distinct symptomatic profiles, ${ }^{5}$ there remains no standard clinical test to differentiate these conditions. ${ }^{6}$

Psychosocial risk factors have long been suggested to play an important role in the development of psychotic illness, ${ }^{7-10}$ and it is possible that different risk factors might underlie affective and SZ psychoses, and that these could be used to improve diagnostic accuracy at first presentation in psychosis patients. This has the potential to significantly improve long-term management. ${ }^{11}$ Most research to date on the association of psychosocial risk factors with psychosis has focused on SZ psychoses. ${ }^{12-15}$ There have, in addition, been several studies comparing psychosocial factors in SZ, manic (MP) and schizoaffective (SA) psychoses in FEP. ${ }^{16-24}$

There are a relatively small number of studies examining psychosocial factors in FEP patients with depressive psychosis (DP). ${ }^{25-28}$ Interestingly, two of these studies found that there were more overlapping features between patients with depressive psychosis (DP) and SZ than with bipolar disorder. ${ }^{27,} 28$ This contradicted the general assumption that patients with DP are often in the early stages of bipolar disorder. ${ }^{29}$ These findings may enable clinicians to recognise and differentiate between MP, SZ and DP at an earlier stage, ultimately influencing future management and recovery. In this study, we aimed to test the hypothesis that different clinical diagnoses at 1 year in FEP patients taken on by Early 
Intervention in psychosis Services (EIS) in London were associated with distinct sociodemographic and clinical features at first presentation.

\section{Methods}

Data were drawn from MiData, a computerized audit tool based within Microsoft Access which was developed by the London Early Intervention Research Network. ${ }^{30}$ Baseline measures were completed by clinicians based on their routine comprehensive assessments within 1 month of entry to EIS (baseline) and then 1 year later (follow-up). All clinicians were trained and were expected to reach at least $85 \%$ concordance with expert raters and other team members before being allowed to complete the measures on their patients. ${ }^{30}$

The MiData database comprises a naturalistic cohort of referrals to seven inner-city EIS from the following NHS (National Health Service) Mental Health Trusts in England: Camden and Islington (C\&I EIS); South London and Maudsley (Lewisham EIS and STEP); South West London and St. George's (Wandsworth); East London and the City (EQUIP); and Central and North West London (Brent and Kensington, Chelsea \& Westminster EIS). Service eligibility criteria were: (i) aged between 18 and 35 years old; (ii) presenting to the EIS for the first time with a psychotic episode lasting at least 7 days; and (iii) resident within the EIS catchment area. Patients with psychotic symptoms as a direct result of acute drug intoxication were excluded. There were 1108 patients in total in the MiData database.

Basic demographic data were obtained at baseline, including gender, age at entry to EIS, educational level, employment status, whether born in the UK, and ethnicity based on the 2001 UK national census categories. Participants were assessed for the presence or absence of: (i) family history of psychosis or any other mental illness in a first-degree relative; (ii) any incidents of violence towards others in their lifetime. 
The degree of hostility in the preceding 2 weeks before presentation was assessed using the Brief Psychiatric Rating Scale. ${ }^{31}$ This variable was quantitatively rated from 1 (none) to 7 (extremely severe). Substance use was measured with the combined alcohol use and drug use scale. ${ }^{32}$ The lifetime use of Alcohol, Nicotine and Cannabis ('yes'/'no' for each) was recorded at presentation.

Duration of Untreated Psychosis (DUP) was assessed with a revised version of the Nottingham Onset Schedule. ${ }^{33}$ DUP was defined as: the number of days between the appearance of the first positive psychotic symptom (hallucination, delusion or thought disorder) and the date that antipsychotic medication was initiated and thereafter reported to have been taken for at least $75 \%$ of the subsequent month.

The Positive and Negative Syndrome Scale (PANSS) ${ }^{34}$ was completed by clinicians at baseline to assess positive (PANSS-P) and negative (PANSS-N) psychotic symptoms. The Young Mania Rating Scale (YMRS) ${ }^{35}$ was completed to assess manic symptoms. The Global Assessment of Functioning Scale disability subscale (GAF-d $)^{36}$ was also completed at baseline.

ICD-10 (International Classification of Diseases-10) ${ }^{37}$ diagnosis was recorded at 1 -year follow up and was extracted from clinical records and confirmed with EIS consultant psychiatrists. These were grouped into schizophrenia-spectrum disorders (SZ) (ICD-10 codes F20-29), manic psychoses (MP) (F30.2, F31.2 or F31.5), depressive psychoses (DP) (F32.3, F33.3 or F39), and other disorders (OD) (all other codes).

\section{Ethical Approval}

Data were collected by each EIS in accordance with local audit procedures, which did not require patients to consent to collection of the data. Multi-centre ethical permission for secondary research use of anonymized versions of these datasets was provided by the 
Wandsworth Research Ethics Committee. HLF merged together the anonymized data supplied by each EIS following written consent from the team managers.

\section{Missing Data}

The supplementary tables reveal the distribution of missing data for each variable between the diagnostic categories. Any variable with greater than $50 \%$ missing data was not included in the subsequent analyses. Chi-square tests were performed to reveal any variables with statistically significant differences in missing data between the diagnostic subgroups; any such variables were also excluded from the subsequent analyses.

\section{Data Analysis}

The clinical diagnosis at follow-up remained the independent variable throughout. The subgroups were initially compared using standard baseline demographic variables: age, gender and ethnicity. Additional baseline variables were selected for further subgroup comparison. These variables were selected as they either a) presented significant results based on a preliminary comparison of all 148 baseline variables or b) were comparable factors used in prior studies comparing FEP patients with SZ, DP and MP. A final evaluation by Team was conducted to check for bias in the audit data collection.

Analysis for this paper was conducted using SPSS version 22 for Windows. Results are expressed as: mean (standard deviation) for continuous variables and as frequency $n(\%)$ for categorical variables. The $p$ value was calculated for each dependent variable using standard procedures; statistical significance was set at $p<0.05$. Histogram, box plots and QQ plots were used to assess for normality and outliers. For continuous variables, a oneway analysis of variance (ANOVA) test was used. The effect size was measured with the omega-squared measure $\left(w^{2}\right)$, rather than eta-squared, to reduce bias. For categorical variables, the Pearson chi-square test for association $\left(x^{2}\right)$ was used. The effect size for categorical variables (odds ratio) was not calculated as the contingency tables were always 
greater than $2 \times 2$. Post-hoc analysis using Tukey's honestly significant difference (HSD) test was performed on variables with statistically significant ANOVA values and a Bonferroni correction was used to account for multiple testing. Missing cases were automatically excluded by SPSS for each analysis.

\section{Results}

In total, 1014 patients in the MiData database had a diagnosis recorded at 1 year $(92 \%$ of patients in database). Of these, $76 \%$ were categorised as $\mathrm{SZ}(\mathrm{N}=770), 9 \%$ as $\mathrm{MP}(\mathrm{N}=93)$, $6 \%$ as DP $(\mathrm{N}=60)$ and $9 \%$ as OD $(\mathrm{N}=91)$. As the heterogeneous nature of the OD subgroup would prevent any robust interpretation of the results, these patients were excluded to allow for a clearer comparison of the remaining three subgroups $(N=923)$. The majority of the remaining cohort was male $(n=598,65 \%)$, and the mean age at presentation was 23 years old $(S D=4.7)$. The only significant difference between different EIS was that the Camden and Islington service had a lower proportion of SZ patients than the Wandsworth (ETHOS) and Hackney (EQUIP) services (Table 1).

There were significant differences between the diagnostic subgroups for age, gender and ethnicity at presentation (Table 2). Patients with a diagnosis at 1 year of MP were the youngest at presentation (mean $[S D]=22.4$ [4.6]), with a greater proportion of female patients (46\% male). SZ patients were predominantly male (68\%) and DP patients were the oldest.

There were significant distinctions at presentation for a number of other variables. Level of hostility was higher in SZ than DP $(p<0.05)$, although there was also a non-significant trend for hostility in MP to be higher than in DP $(p<0.1)$. DUP was lower in MP than SZ or DP $(p<0.05)$. Level of education was higher in MP than DP $(p<0.05)$. SZ patients presented with a significantly higher incidence of violence in lifetime than DP patients $(p<0.05)$. 
The three diagnostic subgroups did not differ on country of birth, family history of psychosis or any mental illness, employment status, alcohol use, cannabis use and nicotine use (Table 2).

Table 3 shows a breakdown of the clinical measures at baseline. There was a significant difference in baseline PANSS-P scores $(F(2,535)=5.27, p=0.005, w=0.13)$, PANSS negative scores $(F(2,514)=6.73, p=0.001, w=0.15)$ and YMRS scores $(F(2,532)=$ 24.24, $p<0.001, w=0.28$ ) between diagnostic groups at 1 year. There were no significant baseline differences between the subgroups in GAF-d score.

Post-hoc analysis revealed that MP patients had a lower PANSS-N score (mean (SD) $=12.7$ (5.55)) than SZ (mean (SD) $=17.0(8.21), p=0.001)$ and DP patients (mean (SD) $=17.3$ (8.15), $p=0.019)$. They also had a greater YMRS score than DP and SZ patients (mean $(S D)=17.8(14.04)$, both p's $<0.001)$, and a greater PANSS-P score (mean $(S D)=20.9$ (8.86)) than DP patients (mean $(S D)=15.7(5.31), p=0.004)$.

\section{Discussion}

This is the largest study to date investigating the sociodemographic and clinical features of MP, DP and SZ patients at first presentation to EIS in London. A key proportion of patients were differentiated from SZ patients as MP (9\%), DP (6\%) and OD (9\%) at 1 year. The proportion of patients with each diagnosis did not differ significantly between any of the EIS apart from Camden and Islington, most likely due to a difference in referral pattern or acceptance thresholds.

We found that MP patients differed most markedly from the SZ and DP subgroups, having shorter DUP, higher ratings on the YMRS, and lower negative symptoms (as measured by PANSS-N). The use of DUP as a measure of time should be interpreted with caution as it 
excludes any change in mood symptoms, which may present months before an acute manic episode. ${ }^{38}$ Our finding that DP and SZ patients were more similar to each other than to MP patients is in keeping with earlier reports comparing psychosocial risk factors and psychopathology in FEP patients. ${ }^{27,28}$ It is important, however, to appreciate the potential limitations of using the PANSS to assess negative symptoms in patients with depression. Confounding features shared between depression and negative symptoms diminish its specificity, especially as other key domains of negative symptomatology are absent. ${ }^{39}$ Thus the relatively higher PANSS-N scores in the DP group in this study may have been due, at least in part, to depressive rather than negative symptoms.

In this study, the baseline demographics of each diagnostic subgroup were generally in keeping with previous reports: the majority of patients with SZ were black males of African origin; ;, 16, 18, 19, 23-26, 28 MP patients were youngest at presentation but had achieved the highest level of education; ${ }^{16,18,23,26}$ MP patients had shorter DUP, and subsequently better outcomes. ${ }^{25,40,41}$

The number of baseline variables producing a statistically significant difference involving all three diagnostic subgroups was limited. Furthermore, the calculated effect size of these differentiating variables was often small. These results underscore the multifaceted aetiology of these conditions and demonstrate the degree of overlap between the subgroups. In this study, SZ patients often occupied an intermediate level between DP and MP patients, and previous research has already proposed schizoaffective disorder as the intermediate between SZ and MP. ${ }^{19}, 22-24$ These findings contribute to the ongoing discussion concerning the existence of a psychosis spectrum. ${ }^{9,14}$

The idea of the psychosis continuum has been developed as an alternative approach to categorical diagnosis in psychotic illness. It argues that the psychopathological profile at 
presentation is a better predictor of outcome than diagnostic subgroup, ${ }^{42-44}$ and highlights a subset of the population with psychotic symptoms below the DSM criteria. ${ }^{9}$ The diagnostic stability of the subgroups has also previously been questioned, ${ }^{3}$ although a recent study reaffirmed the high diagnostic stability of SZ and affective psychoses. ${ }^{45}$ Furthermore, patients with first-episode psychosis generally prefer to be told their diagnosis. ${ }^{46}$ Nonetheless, it is worth remembering that future work will possibly redefine diagnostic categories in psychiatry based on underlying biological processes rather than superficial psychopathology. ${ }^{47}$

Although this study illustrates the potential overlap in psychosocial variables, there were significant differences at presentation between the subgroups, supporting a more categorical distinction. ${ }^{48}$ Ultimately, the critical objective is optimal treatment management. Studies have already illustrated the variable response to Lithium by SZ patients compared to bipolar patients. ${ }^{49}$ Further evaluation of the diagnostic stability, reliability and prognostic value of the diagnostic subgroups is required to determine the best outcome of this debate.

Although this naturalistic study design contained a large cohort, and was therefore reasonably representative of the study population, there were a number of limitations which deserve attention. The first set of limitations relate to the collection of the primary data used. The audit data was compiled by clinicians, not researchers. The current study centres around the clinical diagnosis at follow-up, however the factors employed to determine this outcome are largely unknown. For example, it would have also been interesting to note any changes to the preliminary working diagnosis. Additionally, the relatively small sample size of MP and DP patients warrants replication of these results using larger cohorts of patients with these diagnoses. Finally, the dataset contained a large amount of missing data; it is possible that a number of variables were not representative of the population. However, this bias was minimised as (i) the key demographics of the missing data did not vary from those of the whole cohort, (ii) no more than $50 \%$ of data was missing for any variable and (iii) there 
were no significant differences in missing data between the diagnostic subgroups. Missing data is common for audit data, especially in those of longitudinal design.

\section{Conclusion}

Patients presenting to EIS in London show distinct differences in both demographic variables and psychopathology at presentation between those who are eventually diagnosed with DP, MP and SZ. These findings may provide clinicians with supplementary tools to more accurately classify psychosis at initial presentation and design appropriate packages of care. In particular, early and accurate diagnosis of DP patients is critical; this condition is often underreported and undertreated. ${ }^{50}$ Further work to elucidate distinctions in the pathogenesis and aetiology of each disorder is vital to our understanding of these complex conditions.

\section{Acknowledgements}

Initial pilot work on the MiData package within Camden \& Islington Early Intervention Services was supported by Islington Primary Care Trust. We are extremely grateful to clinicians and patients from the participating teams for their time and enthusiasm. We would particularly like to acknowledge the contributions of Kate Theodore, Tom Grange, Katharine McLoughlin, Lorna Hobbs, Peggy Papada, Sally Bloy, Kelso Cratsley, Laurence Church, Rhianne Doherty, Sharif Ghali, Sasha Gold, Farhana Mann, Andrew Tapfumaneyi, Denise Bevan, Lisa Gaiotto, Peter Bailey, Jana Advani, Teuta Rexhepi, Charlie Heriot-Maitland, Mima Simic and Sujata Soni to collection of data in the individual sites. Thanks also to members of LEIRN, especially Paddy Power, Swaran Singh, Aurelie Freeman, Maxine Sacks, Gillian Paul, Brock Chisholm, Emma Stinton and Jim O'Donnell for their contributions to the development and implementation of the package.

\section{Financial Support}

This work was supported by the NIHR Biomedical Research Centre for Mental Health at the South London and Maudsley NHS Foundation Trust and Institute of Psychiatry, King's 
College London. The research received no specific grant from any funding agency, commercial or not for profit sectors.

\section{Conflict of Interest}

None

\section{Ethical Standards}

The authors assert that all procedures contributing to this work comply with the ethical standards of the relevant national and institutional committees on human experimentation and with the Helsinki Declaration of 1975, as revised in 2008. 
Table 1: The diagnostic outcomes allocated from each of the seven London-based EIS teams

\begin{tabular}{|c|c|c|c|c|c|}
\hline \multirow[b]{3}{*}{ EIS, $n(\%)$} & \multicolumn{4}{|c|}{ Clinical diagnosis } & \multirow[b]{2}{*}{$x^{2}(\mathrm{df})$} \\
\hline & $n$ & $\begin{array}{c}S Z \\
N=770\end{array}$ & $\begin{array}{c}\mathrm{MP} \\
\mathrm{N}=93\end{array}$ & $\begin{array}{c}\mathrm{DP} \\
\mathrm{N}=60\end{array}$ & \\
\hline & & & & & $x^{2}=27.60(12)^{*}$ \\
\hline C\&I & 232 & $177(76.3)$ & $29(12.5)$ & $26(11.2)$ & \\
\hline EQUIP & 140 & $125(89.3)$ & $10(7.1)$ & $5(3.6)$ & \\
\hline ETHOS & 107 & $98(91.6)$ & $5(4.7)$ & $4(3.7)$ & \\
\hline KCW & 101 & 78 (77.2) & $14(13.9)$ & $9(8.9)$ & \\
\hline Lewisham & 239 & $202(84.5)$ & 27 (11.3) & $10(4.2)$ & \\
\hline STEP & 79 & $70(88.6)$ & $6(7.6)$ & $3(3.8)$ & \\
\hline Brent & 25 & $20(80.0)$ & $2(8.0)$ & $3(12.0)$ & \\
\hline $\begin{array}{l}\text { Significant } \\
\text { differences } \\
\text { between }\end{array}$ & & $\begin{array}{c}E T H O S \\
E Q U I P>C \& I\end{array}$ & & & \\
\hline groups & & & & & \\
\hline
\end{tabular}

n, frequency; $P, P$-value $\left({ }^{*}<0.05,{ }^{* *}<0.005,{ }^{* * *}<0.001\right) ; S Z$, schizophrenia-spectrum; MP, manic psychosis; DP, depressive psychosis; EIS, Early Intervention Service; C\&I, Camden \& Islington EIS; EQUIP, Hackney EIS; ETHOS, Wandsworth EIS; KCW, Kensington, Chelsea \& Westminster EIS; STEP, Southwark EIS; Brent, London borough of Brent EIS. 
Table 2: Sociodemographic characteristics at baseline for cases based on follow-up diagnosis

\begin{tabular}{|c|c|c|c|c|c|c|}
\hline & \multirow[t]{2}{*}{$n$} & \multicolumn{3}{|c|}{$\begin{array}{l}\text { Clinical diagnosis } \\
\mathrm{N}=923\end{array}$} & \multirow[b]{2}{*}{$F / X 2(d f)$} & \multirow[b]{2}{*}{$\begin{array}{l}\text { Significant } \\
\text { differences } \\
\text { between } \\
\text { groups }\end{array}$} \\
\hline & & $\begin{array}{l}\mathrm{SZ} \\
\mathrm{N}=770\end{array}$ & $\begin{array}{l}\mathrm{MP} \\
\mathrm{N}=93\end{array}$ & $\begin{array}{l}\mathrm{DP} \\
\mathrm{N}=60\end{array}$ & & \\
\hline $\begin{array}{l}\text { Age, years, } \\
\text { mean (SD) }\end{array}$ & 922 & $23.3(4.7)$ & $22.4(4.6)$ & $24.7(5.4)$ & $4.47(2)^{*}$ & $\mathrm{DP}>\mathrm{MP}$ \\
\hline Gender, $\boldsymbol{n}(\%)$ & & & & & $\begin{array}{l}x 2=25.34 \\
(2)^{* \star *}\end{array}$ & \\
\hline Male & 598 & $526(68.3)$ & $43(46.2)$ & $29(48.3)$ & & $\begin{array}{l}\mathrm{SZ}>\mathrm{MP} \\
\mathrm{DP}\end{array}$ \\
\hline Female & 325 & 224 (31.7) & $50(53.8)$ & $31(51.7)$ & & $\begin{array}{l}\text { MP, DP > } \\
S Z\end{array}$ \\
\hline $\begin{array}{l}\text { Ethnicity, } n \\
(\%)\end{array}$ & & & & & $\begin{array}{l}x^{2}=25.68 \\
(14)^{*}\end{array}$ & \\
\hline White British & 187 & $157(20.4)$ & $14(15.1)$ & $16(26.7)$ & & \\
\hline White Other & 104 & $76(9.9)$ & $13(14.0)$ & $15(25.0)$ & & $\mathrm{DP}>\mathrm{SZ}$ \\
\hline Mixed & 82 & $68(8.9)$ & $11(11.8)$ & $3(5.0)$ & & \\
\hline Asian & 103 & $90(11.7)$ & $9(9.7)$ & $4(6.7)$ & & \\
\hline Black & 94 & $80(10.4)$ & $10(10.8)$ & $4(6.7)$ & & \\
\hline \multicolumn{7}{|l|}{ Caribbean } \\
\hline Black African & 246 & $213(27.7)$ & $20(21.5)$ & $13(21.7)$ & & \\
\hline Black Other & 74 & $60(7.8)$ & 12 (12.9) & $2(3.3)$ & & \\
\hline Other & 31 & $24(3.1)$ & $4(4.3)$ & $3(5.0)$ & & \\
\hline $\begin{array}{l}\text { DUP, days, } \\
\text { mean (SD) }\end{array}$ & 615 & $\begin{array}{l}104.8 \\
(113.1)\end{array}$ & $31.3(38.1)$ & $\begin{array}{l}116.1 \\
(120.0)\end{array}$ & $13.72(2)^{\star \star *}$ & $\begin{array}{l}\mathrm{MP}<\mathrm{SZ} \\
\mathrm{DP}\end{array}$ \\
\hline $\begin{array}{l}\text { Hostility, } \\
\text { mean (SD)1 }\end{array}$ & 648 & $2.3(1.8)$ & $2.3(1.9)$ & $1.6(0.9)$ & $4.14(2)^{*}$ & $S Z>D P$ \\
\hline $\begin{array}{l}\text { Education }{ }^{2}, \\
\text { mean (SD) }\end{array}$ & 794 & $2.9(1.8)$ & $3.2(1.9)$ & $2.5(1.5)$ & $2.82(2)$ & $\mathrm{MP}>\mathrm{DP}$ \\
\hline $\begin{array}{l}\text { Born in UK, } n \\
(\%)\end{array}$ & & & & & $x^{2}=4.03(2)$ & \\
\hline Yes & 527 & $446(60.8)$ & $53(60.2)$ & $28(47.5)$ & & \\
\hline No & 354 & 288 (39.2) & $35(39.8)$ & 31 (52.5) & & \\
\hline $\begin{array}{l}\text { FH of } \\
\text { Psychosis, } n \\
\text { (\%) }\end{array}$ & & & & & $x^{2}=0.54(2)$ & \\
\hline Yes & 176 & $148(22.0)$ & $18(24.3)$ & $10(18.9)$ & & \\
\hline No & 623 & $524(78)$ & $56(75.7)$ & $43(81.1)$ & & \\
\hline \multicolumn{5}{|c|}{ FH of any mental illness, $n(\%)$} & $x^{2}=1.71(2)$ & \\
\hline Yes & 170 & 140 (20.9) & $20(27.0)$ & $10(18.9)$ & & \\
\hline No & 628 & $531(79.1)$ & $54(73.0)$ & $43(81.1)$ & & \\
\hline \multicolumn{4}{|c|}{ Employment status, $n$ (\%) } & & $x^{2}=3.15(4)$ & \\
\hline Employed & 121 & $100(14.2)$ & $11(13.8)$ & $10(17.5)$ & & \\
\hline Unemployed & 537 & $456(64.9)$ & $46(57.5)$ & $35(61.4)$ & & \\
\hline Other & 182 & $147(20.9)$ & $23(28.7)$ & $12(21.1)$ & & \\
\hline \multicolumn{4}{|c|}{ Violence in lifetime, $n(\%)$} & & $x^{2}=6.63(2)^{*}$ & \\
\hline Yes & 249 & $219(40.9)$ & $21(38.9)$ & $9(20.9)$ & & $S Z>D P$ \\
\hline No & 384 & 317 (59.1) & $33(61.1)$ & 34 (79.1) & & $D P>S Z$ \\
\hline
\end{tabular}


Alcohol use, $n$ (\%)

\begin{tabular}{|c|c|c|c|c|c|}
\hline \multicolumn{5}{|c|}{ Alcohol use, $n(\%)$} & \multirow[t]{2}{*}{$x^{2}=3.71$} \\
\hline Yes & 333 & $275(57.5)$ & $36(67.9)$ & $22(48.9)$ & \\
\hline No & 243 & $203(42.5)$ & $17(32.1)$ & $23(51.1)$ & \\
\hline \multicolumn{5}{|c|}{ Nicotine use, $\boldsymbol{n}(\%)$} & \multirow[t]{3}{*}{$x^{2}=1.42(2)$} \\
\hline Yes & 210 & $179(37.5)$ & $18(34.6)$ & $13(28.9)$ & \\
\hline No & 364 & $298(62.5)$ & $34(65.4)$ & $32(71.1)$ & \\
\hline \multicolumn{5}{|c|}{ Cannabis use, $n(\%)$} & \multirow[t]{3}{*}{$x^{2}=3.35(2)$} \\
\hline Yes & 330 & $279(58.5)$ & $31(58.5)$ & $20(44.4)$ & \\
\hline No & 245 & $198(41.5)$ & $22(41.5)$ & $25(55.6)$ & \\
\hline
\end{tabular}

$n$, frequency; SZ, schizophrenia-spectrum; MP, manic psychosis; DP, depressive psychosis; GAF-d, Global Assessment of Functioning Scale-disability subscale; PANSS, Positive and Negative Syndrome Scale; YMRS, Young Mania Rating Scale; DUP, Duration of Untreated Psychosis (time between first psychotic symptom and compliance with medication); $P, p$-value $\left(^{*}<0.05,{ }^{* *}<0.005,{ }^{* * *}\right.$ $<0.001)$; df, degrees of freedom; $S D$, standard deviation; ' , degree of symptom in preceding 2 weeks (0-7); 2, highest level of qualification scale (1-7): no qualifications (1), GCSES (2), A-levels (3), professional qualification/Higher National Diploma (4), degree incomplete (5), degree complete (6), post-grad training (7); FH, family history. 
Table 3: Clinical measures breakdown at baseline and follow-up based on clinical diagnosis at 1 year.

\begin{tabular}{|c|c|c|c|c|c|c|}
\hline & \multirow[b]{2}{*}{$n$} & \multicolumn{3}{|c|}{$\begin{array}{l}\text { Clinical diagnosis } \\
N=923\end{array}$} & \multirow[b]{2}{*}{$F(\mathrm{df}=2)$} & \multirow[b]{2}{*}{$\begin{array}{l}\text { Significant } \\
\text { differences } \\
\text { between } \\
\text { groups }\end{array}$} \\
\hline & & $\begin{array}{l}S Z \\
N=770\end{array}$ & $\begin{array}{l}\mathrm{MP} \\
\mathrm{N}=93\end{array}$ & $\begin{array}{l}\mathrm{DP} \\
\mathrm{N}=60\end{array}$ & & \\
\hline \multicolumn{7}{|c|}{ PANSS-P, mean (SD) } \\
\hline $\begin{array}{l}\text { Baseline } \\
\text { PANSS-N }\end{array}$ & $\begin{array}{l}538 \\
\text { mean }\end{array}$ & $18.4(7.7)$ & $20.9(8.9)$ & $15.7(5.3)$ & $5.27^{\star *}$ & $\mathrm{DP}<\mathrm{MP}$ \\
\hline Baseline & 517 & $17.0(8.2)$ & $12.7(5.6)$ & $17.3(8.1)$ & $6.73^{\star \star \star}$ & $\begin{array}{l}\mathrm{MP}<\mathrm{SZ} \\
\mathrm{DP}\end{array}$ \\
\hline \multicolumn{7}{|c|}{ YMRS, mean (SD) } \\
\hline Baseline & 535 & $9.2(8.5)$ & $17.8(14.0)$ & $6.0(5.3)$ & $24.24^{\star * *}$ & $\begin{array}{l}\mathrm{MP}>\mathrm{SZ} \\
\mathrm{DP}\end{array}$ \\
\hline \multicolumn{7}{|c|}{ GAF-d, mean (SD) } \\
\hline Baseline & 537 & $49.9(17.7)$ & $52.2(18.9)$ & $47.1(16.2)$ & 0.96 & \\
\hline
\end{tabular}




\section{References}

1. Cuthbert BN, Insel TR. Toward the future of psychiatric diagnosis: the seven pillars of RDoC. BMC medicine. 2013; 11: 1.

2. Phillips ML, Kupfer DJ. Bipolar disorder diagnosis: challenges and future directions. The Lancet. 2013; 381: 1663-71.

3. Owoeye O, Kingston T, Scully PJ, et al. Epidemiological and clinical characterization following a first psychotic episode in major depressive disorder: comparisons with schizophrenia and bipolar I disorder in the Cavan-Monaghan First Episode Psychosis Study (CAMFEPS). Schizophrenia bulletin. 2013; 39: 756-65.

4. Carlson GA, Fennig S, Bromet EJ. The confusion between bipolar disorder and schizophrenia in youth: where does it stand in the 1990s? Journal of the American Academy of Child \& Adolescent Psychiatry. 1994; 33: 453-60.

5. $\quad$ Craddock N, Sklar P. Genetics of bipolar disorder. The Lancet. 2013; 381: 1654-62.

6. Kapur S, Phillips AG, Insel TR. Why has it taken so long for biological psychiatry to develop clinical tests and what to do about it\&quest. Molecular psychiatry. 2012; 17: 1174-9.

7. Fusar-Poli P, Bonoldi I, Yung AR, et al. Predicting psychosis: meta-analysis of transition outcomes in individuals at high clinical risk. Archives of general psychiatry. 2012; 69: 220-9.

8. Morgan C, Kirkbride J, Hutchinson G, et al. Cumulative social disadvantage, ethnicity and firstepisode psychosis: a case-control study. Psychological medicine. 2008; 38: 1701-15.

9. Van Os J, Linscott RJ, Myin-Germeys I, Delespaul P, Krabbendam L. A systematic review and meta-analysis of the psychosis continuum: evidence for a psychosis proneness-persistenceimpairment model of psychotic disorder. Psychological medicine. 2009; 39: 179-95.

10. Fisher $\mathrm{HL}$, Jones $\mathrm{PB}$, Fearon $\mathrm{P}$, et al. The varying impact of type, timing and frequency of exposure to childhood adversity on its association with adult psychotic disorder. Psychological medicine. 2010; 40: 1967-78.

11. Spencer E, Birchwood M, McGovern D. Management of first-episode psychosis. Advances in Psychiatric Treatment. 2001; 7: 133-40.

12. Ayesa-Arriola R, Rodríguez-Sánchez JM, Suero ES, Reeves LE, Tabarés-Seisdedos R, CrespoFacorro B. Diagnosis and neurocognitive profiles in first-episode non-affective psychosis patients. European archives of psychiatry and clinical neuroscience. 2016: 1-10.

13. Compton MT, Kelley ME, lonescu DF. Subtyping first-episode non-affective psychosis using four early-course features: potentially useful prognostic information at initial presentation. Early intervention in psychiatry. 2014; 8: 50-8.

14. Crow T. The continuum of psychosis and its genetic origins. The sixty-fifth Maudsley lecture. The British Journal of Psychiatry. 1990; 156: 788-97.

15. Jablensky A. Subtyping schizophrenia: implications for genetic research. Molecular psychiatry. 2006; 11: 815-36.

16. Cannon $\mathrm{M}$, Jones $\mathrm{P}$, Gilvarry $\mathrm{C}$, et al. Premorbid social functioning in schizophrenia and bipolar disorder: similarities and differences. American Journal of Psychiatry. 1997; 154: 1544-50.

17. Murray RM, Sham P, Van Os J, Zanelli J, Cannon M, McDonald C. A developmental model for similarities and dissimilarities between schizophrenia and bipolar disorder. Schizophrenia research. 2004; 71: 405-16.

18. Strauss GP, Vertinski M, Vogel SJ, Ringdahl EN, Allen DN. Negative symptoms in bipolar disorder and schizophrenia: A psychometric evaluation of the brief negative symptom scale across diagnostic categories. Schizophrenia research. 2016; 170: 285-9.

19. Benabarre A, Vieta E, Colom F, Martinez-Aran A, Reinares M, Gasto C. Bipolar disorder, schizoaffective disorder and schizophrenia: epidemiologic, clinical and prognostic differences. European Psychiatry. 2001; 16: 167-72. 
20. Cheniaux E, Landeira-Fernandez J, Telles LL, et al. Does schizoaffective disorder really exist? A systematic review of the studies that compared schizoaffective disorder with schizophrenia or mood disorders. Journal of Affective Disorders. 2008; 106: 209-17.

21. Conus P, Cotton S, Schimmelmann BG, McGorry PD, Lambert M. The First-Episode Psychosis Outcome Study: premorbid and baseline characteristics of an epidemiological cohort of 661 firstepisode psychosis patients. Early Intervention in Psychiatry. 2007; 1: 191-200.

22. Parellada M, Castro-Fornieles J, Gonzalez-Pinto A, et al. Predictors of Functional and Clinical Outcome in Early-Onset First-Episode Psychosis: The Child and Adolescent First Episode of Psychosis (CAFEPS) Study. The Journal of clinical psychiatry. 2015; 76: 1441-8.

23. Tamminga CA, Ivleva El, Keshavan MS, et al. Clinical phenotypes of psychosis in the BipolarSchizophrenia Network on Intermediate Phenotypes (B-SNIP). American Journal of Psychiatry. 2013.

24. Tondo L, Vázquez $\mathrm{G}$, Baethge $\mathrm{C}$, et al. Comparison of psychotic bipolar disorder, schizoaffective disorder, and schizophrenia: an international, multisite study. Acta Psychiatrica Scandinavica. 2016; 133: 34-43.

25. Hill SK, Reilly JL, Harris MS, et al. A comparison of neuropsychological dysfunction in firstepisode psychosis patients with unipolar depression, bipolar disorder, and schizophrenia. Schizophrenia research. 2009; 113: 167-75.

26. Mojtabai R, Bromet EJ, Harvey PD, Carlson GA, Craig TJ, Fennig S. Neuropsychological differences between first-admission schizophrenia and psychotic affective disorders. American Journal of Psychiatry. 2000; 157: 1453-60.

27. Rosen C, Marvin R, Reilly JL, et al. Phenomenology of first-episode psychosis in schizophrenia, bipolar disorder, and unipolar depression: a comparative analysis. Clinical schizophrenia \& related psychoses. 2012; 6: 145-51A.

28. Heslin M, Desai R, Lappin J, et al. Biological and psychosocial risk factors for psychotic major depression. Social psychiatry and psychiatric epidemiology. 2016; 51: 233-45.

29. Goldberg JF, Harrow M, Whiteside JE. Risk for bipolar illness in patients initially hospitalized for unipolar depression. American Journal of Psychiatry. 2001; 158: 1265-70.

30. Fisher $\mathrm{H}$, Theodore $\mathrm{K}$, Power $\mathrm{P}$, et al. Routine evaluation in first episode psychosis services: feasibility and results from the MiData project. Social psychiatry and psychiatric epidemiology. 2008; 43: 960-7.

31. Overall J, Gorham D. Introduction $\bar{A}$ The Brief Psychiatric Rating Scale (BPRS): Recent developments in ascertainment and scaling. Psychopharmacological Bulletin. 1988; 24.

32. Drake R, Mueser K, McHugo G. Clinician rating scales: alcohol use scale (AUS), drug use scale (DUS), and substance abuse treatment scale (SATS). Outcomes assessment in clinical practice. 1996: 113-6.

33. Singh SP, Cooper JE, Fisher HL, et al. Determining the chronology and components of psychosis onset: The Nottingham Onset Schedule (NOS). Schizophrenia research. 2005; 80: 117-30.

34. Kay SR, Flszbein A, Opfer LA. The positive and negative syndrome scale (PANSS) for schizophrenia. Schizophrenia bulletin. 1987; 13: 261.

35. Young R, Biggs J, Ziegler V, Meyer D. A rating scale for mania: reliability, validity and sensitivity. The British Journal of Psychiatry. 1978; 133: 429-35.

36. Endicott J, Spitzer RL, Fleiss JL, Cohen J. The Global Assessment Scale: a procedure for measuring overall severity of psychiatric disturbance. Archives of general psychiatry. 1976; 33: 76671.

37. World Health Organization. The ICD-10 Classification of Mental and Behavioural Disorders. Diagnostic Criteria for Research. Geneva: World Health Organization; 1993.

38. Correll CU, Hauser M, Penzner JB, et al. Type and duration of subsyndromal symptoms in youth with bipolar I disorder prior to their first manic episode. Bipolar disorders. 2014; 16: 478-92.

39. Tsapakis EM, Dimopoulou T, Tarazi Fl. Clinical management of negative symptoms of schizophrenia: An update. Pharmacol Ther. 2015; 153: 135-47. 
40. Marshall M, Lewis S, Lockwood A, Drake R, Jones P, Croudace T. Association between duration of untreated psychosis and outcome in cohorts of first-episode patients: a systematic review. Archives of general psychiatry. 2005; 62: 975-83.

41. Lloyd-Evans B, Crosby M, Stockton $S$, et al. Initiatives to shorten duration of untreated psychosis: systematic review. The British Journal of Psychiatry. 2011; 198: 256-63.

42. Cardno AG, Rijsdijk FV, Sham PC, Murray RM, McGuffin P. A twin study of genetic relationships between psychotic symptoms. American Journal of Psychiatry. 2002; 159: 539-45.

43. Linscott RJ, Van Os J. Systematic reviews of categorical versus continuum models in psychosis: evidence for discontinuous subpopulations underlying a psychometric continuum. Implications for DSM-V, DSM-VI, and DSM-VII. Annual review of clinical psychology. 2010; 6: 391-419.

44. Pantelis C, Velakoulis D, McGorry PD, et al. Neuroanatomical abnormalities before and after onset of psychosis: a cross-sectional and longitudinal MRI comparison. The Lancet. 2003; 361: 281-8.

45. Fusar-Poli P, Cappucciati M, Rutigliano G, et al. Diagnostic Stability of ICD/DSM First Episode Psychosis Diagnoses: Meta-analysis. Schizophrenia bulletin. 2016: sbw020.

46. Milton AC, Mullan BA. Diagnosis telling in people with psychosis. Curr Opin Psychiatry. 2014; 27: 302-7.

47. Pearlson GD. Etiologic, phenomenologic, and endophenotypic overlap of schizophrenia and bipolar disorder. Annu Rev Clin Psychol. 2015; 11: 251-81.

48. Laursen TM, Munk-Olsen T, Nordentoft M, Mortensen PB. A comparison of selected risk factors for unipolar depressive disorder, bipolar affective disorder, schizoaffective disorder, and schizophrenia from a Danish population-based cohort. The Journal of clinical psychiatry. 2007; 68: 1673-81.

49. Leucht S, Kissling W, McGrath J. Lithium for schizophrenia. The Cochrane Library. 2007.

50. Rothschild AJ, Winer J, Flint AJ, et al. Missed diagnosis of psychotic depression at 4 academic medical centers. The Journal of clinical psychiatry. 2008; 69: 1293-6. 